Please do not remove this page

RMIT

UNIVERSITY

\title{
Palladium nanowire hydrogen sensor based on a SAW transducer
}

Atashbar, Massood; Kalantar-Zadeh, Kourosh; Ippolito, Samuel; Wlodarski, Wojtek

https://researchrepository.rmit.edu.au/esploro/outputs/9921859354701341/filesAndLinks?institution=61RMIT_INST\&index=null

Atashbar, M., Kalantar-Zadeh, K., Ippolito, S., \& Wlodarski, W. (2005). Palladium nanowire hydrogen sensor based on a SAW transducer. Proceedings of the Fourth IEEE Sensors 2005 Conference, 1363-1365.

https://doi.org/10.1109/ICSENS.2005.1597961

Published Version: https://doi.org/10.1109/ICSENS.2005.1597961

Repository homepage: https://researchrepository.rmit.edu.au

(c) 2005 IEEE. Personal use of this material is permitted. However, permission to reprint/republish this material for advertising or promotional purposes or for creating new collective works for resale or redistribution to servers or lists, or to reuse any copyrighted component of this work in other works must be obtained from the IEEE.

Downloaded On 2023/04/26 23:25:46 +1000 


\section{Palladium Nanowire Hydrogen Sensor Based on a SAW Transducer}

\author{
Massood Z. Atashbar \\ Department of Electrical and Computer Engineering, \\ University of Western Michigan, MI, USA \\ massood.atashbar@wmich.edu
}

\author{
Kourosh Kalantar-zadeh, Samual J. Ippolitto, \\ Wojtek Wlodarski \\ School of Electrical \& Computer Engineering, RMIT \\ University, Melbourne, AUSTRALIA \\ kourosh.kalantar@rmit.edu.au
}

\begin{abstract}
Palladium (Pd) nano-wires were synthesized by electro chemical deposition technique. Pd nano-wires were transferred onto a $\mathrm{ZnO} / 36^{\circ} \mathrm{LiTaO}_{3}$ Surface Acoustic Wave (SAW) transducer with an approximate operating frequency of 100 MHz. This operational frequency approximately corresponds to the device's highest conductometric sensitivity. These devices were investigated for hydrogen $\left(\mathrm{H}_{2}\right)$ sensing at the room temperature. It was observed that the device exposure to the $\mathrm{H}_{2}$ gas resulted to a measurable increase in the device operating frequency.
\end{abstract}

\section{INTRODUCTION}

Detection of hydrogen gas is very important for life safety reasons and optimal process control of hydrogen-based energy systems. For industrial applications, sensors must be hydrogen selective and immune to impurity gases commonly present in hydrogen ambient. While a fast response time is a critical requirement for life safety monitoring and is a necessary feature for real-time control of processes that run on rapid duty cycles.

Many of the group VIII transition metals such as nickel, palladium, and platinum absorb hydrogen spontaneously. This absorption alters the electrical and optical properties of these metals. These alterations have been exploited for measuring hydrogen gas concentration. Palladium has a remarkable property of absorbing hydrogen. This absorption of hydrogen causes the electrical properties of palladium to change. Thomas Graham conducted one of the initial tests of the change in electrical conductance of palladium due to hydrogen in 1869 . He reported that the resistance of palladium increased by $\sim 25 \%$ in the presence of hydrogen. Further experiments carried out by Dewar (1878) and Knott (1886) suggested that the change in electrical resistance is proportional to the hydrogen content. The increase in the resistance of palladium on interaction with hydrogen is attributed to the formation of palladium hydride [1]. Reversible changes in the lattice structure of palladium also occur on exposure to hydrogen.

Gas sensing is about surface and interface interactions between the analyte molecules and the sensing material.
Nano-objects with a large surface to volume ratio, such as nano-particles and nano-wires, are potentially very efficient gas sensors.

Ke. et al [2] have shown changes in the conductivity of gold nano-wires upon exposure to different gases. A similar case is also observed with silver, nickel, palladium, etc. These nano-wires can be used in form of connected metal nanowires. Once transferred in a polymer cast, they can operate as sensors. Exposure of these materials to hydrogen gas causes a rapid and reversible decrease in their resistance which is correlated with the gas concentration. In the case of palladium, change in lattice structure causes the nano-sized particles to swell when the hydride is formed, and in the process of expanding, some of them form new electrical connections with their neighbors [3]. The increased number of conducting pathways results in an overall net decrease in resistance.

Favier et al. [4] and Atashbar et al. [5, 6] have developed hydrogen sensors from arrays of palladium nano-wires by electro-deposition. They used highly oriented pyrolytic graphite (HOPG), by exposing to $\mathrm{PdCl}_{2}$ solution and cyclic voltametric to obtain parallel array of nano-wires. These nano-wires were lying on the template surface. Kim et al. [7] deposited nano-wires into nano-pores of anodized aluminium oxide which are perpendicular to the surface. All these sensors are conductometric.

In our work, a layered Surface Acoustic Wave (SAW) device has been employed as the transducing platform for the measurements. Pd nano-wires were deposited onto the active area of this transducer. The transducer was a layered $\mathrm{ZnO} / 36^{\circ} \mathrm{LiTaO}_{3} \mathrm{SAW}$ device operating at approximately $100 \mathrm{MHz}$. This operational frequency approximately corresponds to the device's highest conductometric sensitivity. $\mathrm{Pd}$ nano-wires change both in volume and conductivity upon exposure to $\mathrm{H}_{2}$. As a result, the SAW device provide an excellent platform for sensing applications with such a layer, as it is both sensitive to mass and conductometric changes. 


\section{EXPERIMENTAL}

\section{A. Transducer Fabrication}

\section{1) $\mathrm{SAW}$ device fabrication}

The layered SAW devices were fabricated on a $36^{\circ} \mathrm{LiTaO}_{3}$ wafer. Metal layers of $\mathrm{Au}(1000 \AA)$ and $\mathrm{Ni}$ adhesion layer (200 A) were deposited by electron beam evaporation. A periodicity of $40 \mu \mathrm{m}$ for the interdigital transducers (IDTs) was patterned using a wet-etch process to create a two-port delay line with 38 finger pairs in each port. A $2 \mu \mathrm{m}$ piezoelectric dielectric layer of $\mathrm{ZnO}$ was deposited over the patterned wafer using a RF magnetron sputterer.

Our previous study [8] shows that the maximum conductometric sensitivity is obtained at $2 \mu \mathrm{m}$ (Fig. 1) and maximum mass sensitivity at $4 \mu \mathrm{m}$ layer thicknesses, respectively. As it is believed that the change in conductivity has a larger effect than the change in mass, the thickness corresponding to the maximum conductivity sensitivity was chosen. The $2 \mu \mathrm{m}$ thickness results in an operational frequency of approximately $100 \mathrm{MHz}$.

\section{2) Formation of the sensitive layer}

HOPG is used as a template in our research, as it offers naturally formed, highly ordered, and parallel V-shaped grooves for electrodepositing Pd nanowires. Parallel arrays of $\mathrm{Pd}$ nano-wires were formed by electro-deposition from an aqueous plating solution onto the surface of HOPG. Consequently, the nano-wires were transferred onto the SAW device using polystyrene thin film with an approximate thickness of $100 \mathrm{~nm}$.

\section{RESULTS AND DISCUSSION}

The morphology of the nano-wires was studied using atomic force microscope and scanning electron microscope. Fig. 2. shows force modulation micrograph of the transferred $\mathrm{Pd}$ nanowires onto the SAW structure and the diameter of nano-wires was measured to be approximately $250 \mathrm{~nm}$. Fig. 3 illustrates scanning electron microscope images of the nano-wires. It can be seen that wires are parallel and continuous. The gas sensing properties were examined using different $\mathrm{H}_{2}$ gas concentrations. Fig. 4 shows that the sensor was initially oscillating at $99.562 \mathrm{MHz}$ when exposed to the cycles of $0.5 \%, 1 \%$ and $0.5 \% \mathrm{H}_{2}$ gas purges. The registered frequency shifts of the device to $0.5 \%$ and $1 \% \mathrm{H}_{2}$ gas were approximately and $5 \mathrm{kHz}$ and $9.5 \mathrm{kHz}$, respectively. Responses were repeatable with a complete return to the base line. Both response and recovery times were less than 2 minutes.
The schematic representation of the $\mathrm{Pd}$ nano-wire interaction with $\mathrm{H}_{2}$ and air cycle is shown in Fig. 5. Fig. 5(a) represents the schematic of the continuous $\mathrm{Pd}$ nanowires grains before exposure to $\mathrm{H}_{2}$. It has been previously presented [6] that $\mathrm{Pd}$ exposure to $\mathrm{H}_{2}$ causes significant morphological, topological and volume changes in $\mathrm{Pd}$ metal segments. When the Pd nano-wires are in contact with $\mathrm{H}_{2}$ gas, $\mathrm{Pd}$ absorbs $\mathrm{H}_{2}$ molecules resulting in the expansion of $\mathrm{Pd}$ grains, which is demonstrated in Fig. 5(b). This increase in volume occurs due to the phase transition and the $\mathrm{Pd}$ lattice expansion. This causes compression along the nanowire length which reduces the gaps in grain boundaries thereby lowering the intergranular resistance. By switching to ambient air a reverse phase transition occurs, which causes the contraction of the nano-wire grains. This contraction results in tensile stress, which breaks the nanowires and hence forms nano-size gaps (Fig. 5(c)) which causes a reduction in the conductivity. On re-exposure to $\mathrm{H}_{2}$ the $\mathrm{Pd}$ grains expand, making the nano-wires conductive again (Fig. 5(d)). Showing both conductivity and mass change, Pd nano-wires could form an efficient gas sensing layer for SAW devices.

\section{CONCLUSION}

Pd nanowires were successfully transferred onto layered SAW structure which was tuned to operate at its highest conductive sensitivity. The sensor was tested at room temperature as a result of exposure to 0.5 and $1 \%$ of $\mathrm{H}_{2}$ gas the sensor frequency shift was measured to be $5 \mathrm{kHz}$ and 9.5 $\mathrm{kHz}$, respectively. Its response was reversible and reproducible. The nano-wire array-based $\mathrm{H}_{2}$ sensors have fast response and room-temperature operation. The performance of the nano-wire array-based SAW sensors documented here challenges existing $\mathrm{H}_{2}$ sensing technologies.

\section{REFERENCES}

[1] F. A. Lewis, The Palladium Hydrogen System, New York: Academic, 1967.

[2] C.Z. Li, H. X. He, A. Bogozi, J. S. Bunch and N.J. Tao, "Molecular Detection Based on Conductance Quantization of Nanowires", Appl. Phys. Lett., 76, pp. 1333-1336, 2000.

[3] X. Ke, G. J. Kramer and O. M. Løvvik, "The Influence of Electronic Structure on Hydrogen Absorption in Palladium Alloys," vol. 16Journal of Physics: Condensed Matter, pp: 6267-6273, 2004.

[4] F. Favier, E. C. Walter, M. P. Zach, T. Benter, R. M. Penner, "Hydrogen Sensors and Switches from Electrodeposited Palladium Mesowire Arrays," Science, vol .293, Issue 5538, pp. 2227-2231, 2001

[5] M. Z. Atashbar, D. Banerji, S. Singamaneni, and V. Blinznyuk, "Deposition for Parallel Arrays of Palladium Nanowires and Electrical Characterization using Microelectrode Contacts," Nanotechnology, vol. 15, pp. 374-378, 2004. 
[6] M.Z. Atashbar, D. Banerji, and S. Singamaneni "Room temperature hydrogen sensor based on palladium nanowires", IEEE Sensors Journal, vol. 5, pp. $792-797,2005$.

[7] K. Kim, M. Kim and S. M. Cho, "Pulsed Electrodeposition of Palladium Nanowire Arrays using AAO Template" Materials Chemistry and Physics, 2005, (in press).

[8] K. Kalantar-zadeh, D. Powell, S. Ippolito, W. Wlodarski "Study of Layered SAW Devices Operating at Different Modes for Gas Sensing Applications" the 2004 IEEE International Ultrasonics, pp. 191-194, 2004.

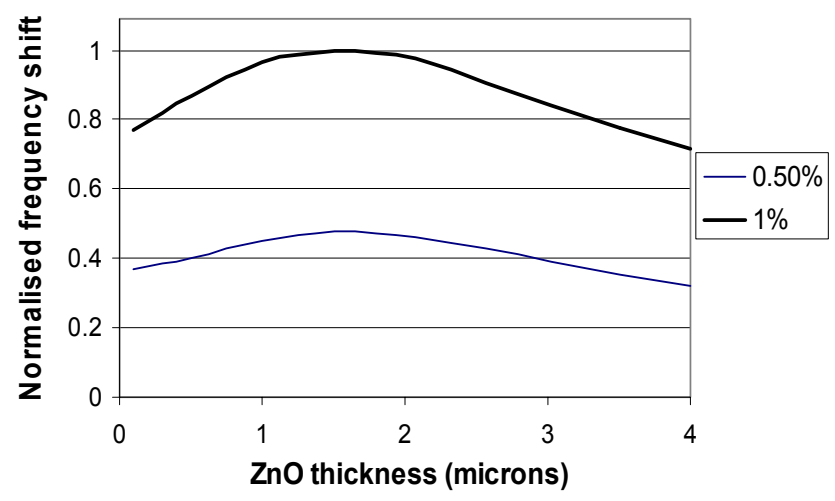

Fig. 1. Sensitivity calculation of $\mathrm{ZnO}$ layer thickness vs the frequency shift after exposure to $0.5 \%$ and $1 \%$ of $\mathrm{H}_{2}$ gas in synthetic air for $\mathrm{f}_{0}=100 \mathrm{MHz}$ device.

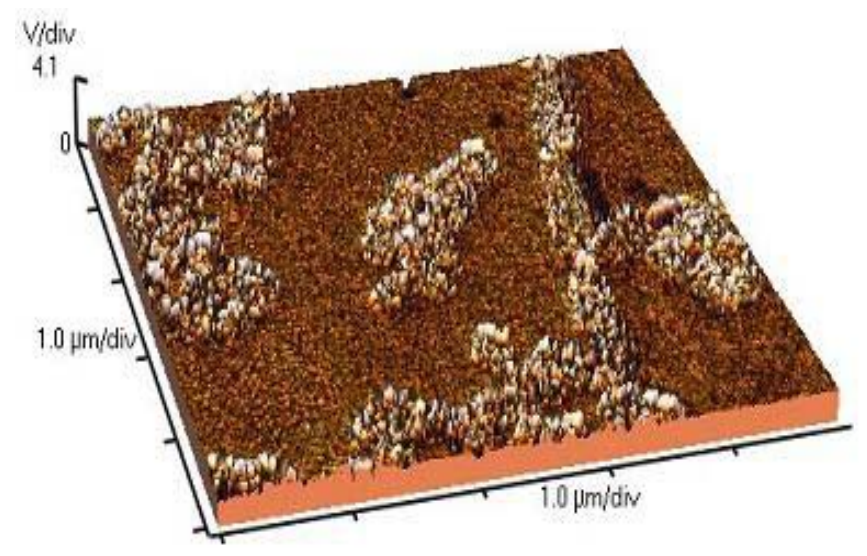

Fig. 2. The atomic force microscope micrograph of transferred nanowires on polystyrene.

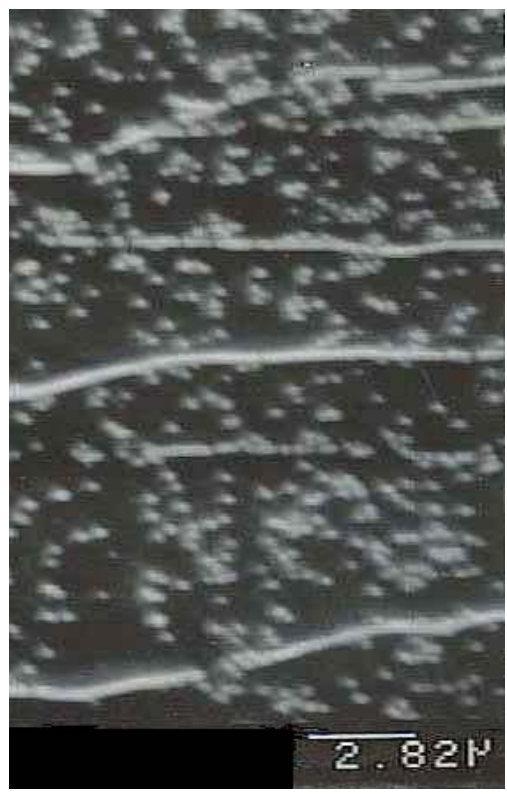

Fig. 3. SEM images of nanowires initially deposited on HOPG.

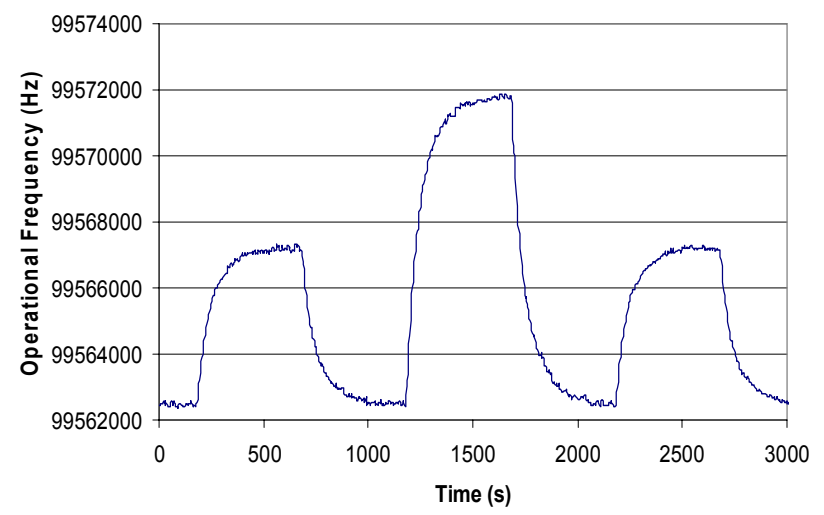

Fig. 4. A response sequence to $0.5 \%$ and $1 \% \mathrm{H}_{2}$ gas.

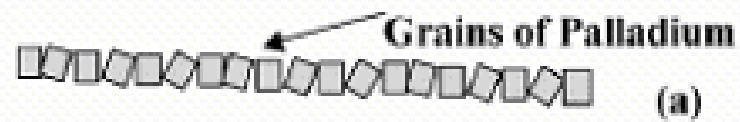

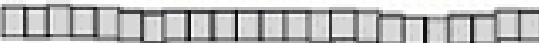

(b)

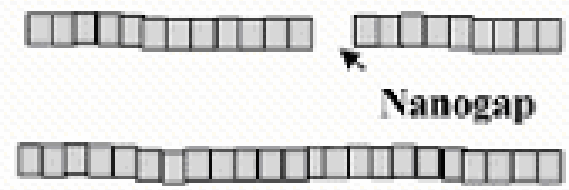

(c)

(d)

Fig. 5. Schematic representation of Pd nano wires upon exposure to $\mathrm{H}_{2}$ gas. 